\title{
Ciência e estética na ciência humboldtiana e os fundamentos da Geografia Física moderna
}

\author{
Antonio Carlos Vitte \\ Roberison Wittgeinstein Dias da Silveira" \\ Kalina Salaib Springer*** \\ Josevan Dutra Gomes
}

\section{Resumo}

O presente trabalho examina os fundamentos artísticos e filosóficos que influenciaram a constituição da ciência humboldtiana, que se constitui geneticamente na base para a organização do pensamento geográfico moderno. A ciência humboldtiana formou-se a partir de um complexo debate que ocorreu no século XVIII, tendo como base o pensamento sobre estética e teleologia de Kant e que se desenvolveu a partir da naturphilosophie com Schelling, Schiller e Goethe. O produto é a geração do conceito de espacialidade, categoria morfológica e estética da representação que permite a comunicação e a geração de conhecimento. Nesse momento, estavam erigidas as bases para a organização da geografia moderna, em termos de objeto e de método.

Palavras-chave: Ciência Humboldtiana; Naturphilosophie; Natureza; Estética; Newton; Geografia.

\footnotetext{
* Departamento e Programa de Pós-Graduação em Geografia, Instituto de Geociências, Unicamp, Campinas - Pesquisador $\mathrm{CNPq}$ (acarlosvitte@uol.com.br).

** Departamento de Geografia, Universidade Federal de Alagoas/ Campus do Sertão (silveira_r@yahoo.com.br).

Doutora em Geografia pelo Programa de Pós-Graduação em Geografia, Instituto de Geociências, Unicamp (springer_kalina@yahoo.com.br).

Mestre em Geografia pelo Programa de Pós-Graduação em Geografia, Instituto de Geociências, Unicamp (josevandutra@ gmail.com).
}

Geosul, Florianópolis, v. 27, n. 54, p 7-32, jul./dez. 2012 
VITTE, A.C. et al. Ciência e estética na ciência humboldtiana e os ...

Science and aesthetic in humboldtian science and the foundations of modern Physical Geography

\section{Abstract}

The present work examines the artistic and philosophical foundations that influenced the humboldtian science constitution that we constituted genetically in the base of the modern geographical thought. The humboldtian science it constituted starting from a complex debate that occurred in century XVIII, having as base the thought about aesthetics and Kant's theleologic and that was developed from the naturphilosophie with Schelling, Schiller and Goethe. The product is spaciality concept generation, morphologic category and representation aesthetics that allows the communication and the knowledge generation. At this moment, they were formed the bases for the organization of the modern geography, in terms of object and of method.

Key words: Humboldtian Science; Naturphilosophie; Nature; Aesthetic; Newton; Geography.

\section{Introdução}

O conceito de natureza em Humboldt é claramente influenciado pelas propostas de Goethe e Schelling. A construção desse conceito remete, na mesma medida, a uma série de pressupostos metodológicos que acabam por ser incorporados na sua proposta de análise. Este artigo pretende justamente mostrar como, para além das colocações gerais da ciência da natureza do período, intentou Humboldt uma construção sistemática que valoriza a questão da forma como síntese e da representação artística, seja, pela pintura ou pela prosa poética, como aportes metodológicos na compreensão do Cosmos. Tem-se, portanto, que a adoção original do conceito de natureza permitiu através do remetimento às construções teleo-estético-filosóficas de Kant e dos românticos alemães, bem como as contribuições de uma ciência 
VITTE, A.C. et al. Ciência e estética na ciência humboldtiana e os ...

filosófico-artística de Goethe, uma incorporação metodológica de uma série de elementos que fizeram da análise de Humboldt um caso particular e, consequentemente, do surgimento moderno da Geografia um reduto de inúmeras controvérsias.

A arte, mais especificamente a questão estética, assume centralidade na passagem do século XVIII para o século XIX, sobretudo pelo papel desempenhado nesse contexto pela Crítica da Faculdade de Julgar de Kant (1995), em que se apresentam uma medida de gosto universal pela imagem do belo, ao mesmo tempo em que se associa essa concepção com a construção de um juízo reflexivo distinto daquele que domina as formas de julgar nas Críticas da Razão Pura e Prática. Essa passagem, a colocação de uma estética moderna em Kant representa um manancial de novas interpretações para os estudos ulteriores acerca da arte e, mais especificamente, para a valorização do elemento estético na construção filosófica e mesmo na ciência. Essa mudança, incorporada e levada a cabo pelo romantismo que toma forma na Alemanha do século XIX, é o cenário no qual se introduz a construção da obra humboldtiana, é o espaço de integração dos diferentes agentes que culminam na Gênese Moderna da Geografia. O primeiro passo na compreensão deste legado em Humboldt e, consequentemente, na identificação do papel que desempenha esse movimento na fundamentação moderna da Geografia, diz respeito à construção dos juízos reflexivos estéticos em Kant.

\section{Forma e estética na Crítica do Juízo: o papel dos juízos reflexivos estéticos}

Na Analítica da Faculdade de Juízo Estética (KANT, 1995), Kant tratará de um elemento importante na estruturação de uma nova maneira de conceber e tratar a natureza. A "forma", seu caráter integrador e não submetido a finalidade imposta pela razão, ao mesmo tempo em que reveladora de uma ligação entre todo e partes, representa um passo decisivo na adoção de uma finalidade 
VITTE, A.C. et al. Ciência e estética na ciência humboldtiana e os ...

própria da natureza. Vejamos, portanto, como o filósofo chega até essa noção de "forma" pelos juízos estéticos.

Os juízos estéticos, em seu caráter puro, têm como primeira e mais importante característica não dependerem de uma finalidade imposta pelo sujeito, ou seja, não visam conceitos da razão. Isso fica claro quando falamos em estética, já que pressupomos aqui um prazer ou desprazer que não é dado pela lógica, mas pela simples experiência desinteressada diante da forma; doutra feita, requer, na perspectiva de Kant, uma universalidade, pelo que não pode ser uma simples atribuição subjetiva. A distinção entre agradável, bom e belo deixa claro essa diferença.

O agradável está ligado às sensações, de maneira que é dada de forma particular e diferenciada de acordo com cada sujeito e em vista de seus interesses específicos; caracteriza, como nos parece evidente, que há sim um interesse em sua determinação, de onde se tira que não é um juízo de gosto puro. Quanto ao que é bom, temos novamente a manifestação de um interesse, nesse caso ligado ou ao que é útil ou ao incondicionado da ação, ao elemento transcendente da razão que empreende a noção de dever moral no homem. No bom, como aquilo que é útil, se revela o objeto como meio, como caminho para a realização de um fim colocado em alguma circunstância ou condição; no bom em si, não se antevê a efetivação de um meio, mas um fim incondicionado e por isso chamado dever. Este último se relaciona com a moral e seus imperativos categóricos, se referindo muito mais ao sujeito do que propriamente ao que aparece como representação. No caso do belo, no entanto, trata-se de reconhecer um prazer desinteressado universal na forma, admitido enquanto tal para além das opiniões ou apetições particulares, levando, no mais das vezes, a confundirse com algo objetivo, quando em verdade é objetivo somente na ligação que estabelece com o sujeito.

O sujeito falará pois, do belo como se a lógica fosse uma qualidade do objeto e o juízo fosse lógico (constituído através de conceitos do obejto um conhecimento do 
VITTE, A.C. et al. Ciência e estética na ciência humboldtiana e os ...

mesmo), conquanto ele seja somente estético e contenha simplesmente uma referência da representação do objeto ao sujeito; porque ele contudo possui semelhança com o lógico, pode-se pressupor a sua validade para qualquer um. (KANT, 1995, p. 44)

O mais interessante e o que coloca Kant no rumo desta discussão é que, justamente pela universalidade que requer, o belo apresenta-se como se fosse dado objetivamente; por isso falamos em coisas belas. Mas acontece que é ainda uma impressão, uma referência subjetiva pela qual julgamos sobre o prazer ou desprazer. Esse caráter paradoxal remete a uma nova forma de juízo, haja vista a incapacidade de se determinar pelas leis do entendimento algo que se refira não ao conhecimento, mas ao prazer e desprazer, e que deva, ainda assim, representar uma universalidade.

Ora, sabemos que prazer e desprazer são de ordem subjetiva, de maneira que reconhecê-los em sua universalidade sem se referir a conceitos é tarefa que não se pode explicar pelos mecanismos dispostos na Primeira Crítica (CRP). O juízo reflexivo estético permite, neste momento, sair do particular dado e chegar ao geral que não foi concedido pelo a priori da razão, mas que ainda assim contém ou revela uma universalidade. Isso é possível porque embora os juízos reflexivos não possuam leis próprias, eles têm, "todavia um princípio próprio para procurar leis..." (KANT, 1995, p.21). A forma é então importante; elemento integrador do todo e das partes na representação do instante, ela nos autoriza a falar em uma universalidade dada pelo particular e que não recorre ao interesse da razão. Antevê-se aqui como explicação a determinação de uma finalidade que envolve a representação sem dizer respeito ao interesse. No juízo de gosto puro, na determinação do belo, o que se vê é um "livre jogo" entre a imaginação e o entendimento na contemplação da forma, permitindo juízos que saiam do particular e assumam validade geral. O belo é tido como um "conceito indeterminado do entendimento" (KANT, 1995, p. 90), pelo que compreendemos que sua regulação seja construída num 
VITTE, A.C. et al. Ciência e estética na ciência humboldtiana e os ...

"livre jogo" desinteressado da imaginação, que é responsável pela composição do múltiplo sem depender do conceito, com o entendimento, que permite a consideração da universalidade objetiva ao mesmo tempo em que não se submete à esta objetividade e às leis que se lhe impõem. Juízos reflexivos estéticos se tornam dessa forma possíveis e nos remetem a um juízo de gosto puro, em que há uma universalidade indeterminada e uma referência direta a uma representação.

Ainda que seja concebido desinteressadamente, o juízo de gosto pode servir a um interesse, o intelectual por exemplo. Isso é possível porque não se revoga aqui a capacidade de julgar intelectual do sujeito; ele consegue agrupar estes juízos estéticos, originalmente sem interesse, no conjunto geral de suas finalidades. Estamos falando, por exemplo, da arte-bela, capaz de aproximar o belo com o interesse intelectual em uma produção que permite inclusive um conhecimento.

Reinterpretando a mimese aristotélica, ou seja o nexo entre arte e natureza na perspectiva do belo como objeto dos juízos de gosto - dos juízos de caráter contemplativo e desinteressado, que permitem qualificar de estética a experiência relativa às coisas naturais e às obras de arte foi Kant quem preparou a excepcional autonomia da noção de gênio. (NUNES In: GUINSBURG, 2002, p. 60)

O gênio assume a importante função de reunir a representação desinteressada estética com o interesse intelectual regulador, de forma que o produto de sua arte, a arte bela, seja a imagem de um talento que consegue representar através da técnica sem que esta seja percebida na obra final. Esta obra deve, portanto, aparecer ao seu interlocutor como simples forma desinteressada, assim como o belo da natureza. Eis aí a arte do gênio.

$\mathrm{O}$ conhecimento se vincula a obra de arte na medida em que o poder criativo da imaginação e a representação desinteressada perfazem um caminho diferente de exposição da natureza, uma vez que a arte não se restringe aos limites e regras impostas pela razão 
VITTE, A.C. et al. Ciência e estética na ciência humboldtiana e os ...

e seus conceitos (MARÍ, 1989). É essa concepção que chega aos românticos na Alemanha do século XIX, e é por ela que Humboldt pensará a valorização da forma e da representação artística como modo mais elevado de se legitimar a síntese da natureza que se propõe.

O primeiro ponto importante na análise da arte em Humboldt diz respeito ao valor que ela assume na vida do homem, o sentido que a associa com a construção do conhecimento e, mais especificamente, na maneira de equilibrar as contribuições da razão com a perspectiva da sensibilidade. Esse primeiro fundamento estético está em Schiller.

\section{Uma nova estética em Schiller: a concepção de homem em Humboldt}

O pensamento de Johann Christoph Friedrich Schiller (17591805) é importante na redefinição do sentido estético e do papel que deve desempenhar ele na atividade humana. Partindo de Kant, aproxima a razão prática e o juízo estético. A princípio parece algo incompatível; como vimos anteriormente, a estética é dada por um livre jogo desinteressado entre a imaginação e o entendimento, tomado na perspectiva intuitiva, ao passo que a razão prática imprime na ação o dever imposto pelo incondicionado numa finalidade bem definida. O que fará Schiller é colocar o estético numa perspectiva determinada e não como livre jogo; deve este apoiar-se em leis assim como ordena o imperativo categórico à razão prática. Contudo, Schiller não pretende aqui a criação de um novo termo na dualidade kantiana, mas o estabelecimento de um equilíbrio, já que parte do pressuposto de ser todo o homem um misto entre razão e sensibilidade. É na consideração básica desse princípio que se edificará a proposta de uma Educação Estética do Homem (SCHILLER, 2002).

$\mathrm{O}$ reino do dever imposto pelo incondicionado é tudo quanto ordena a razão prática na existência moral imposta ao homem. O seu agir, portanto, deve refletir a máxima imposta por uma razão 
VITTE, A.C. et al. Ciência e estética na ciência humboldtiana e os ...

capaz de ordenar para si um sentido e uma forma plena, uma proximidade sempre renovada com o perfeito que orienta o ato moral. Essa vida santa não é questionada por Schiller, realmente às máximas da razão que aludem a uma vida moral pelo dever são de fato imperativos, no entanto, para Schiller, como fizemos questão de mostrar, o homem não é simplesmente razão, é também sensibilidade. É na consideração da existência inelutável da sensibilidade que se elevará o sentido estético, o papel que deve desempenhar ele na consumação da existência plena do humano, o cumprimento mesmo do projeto final de um ser em sua real condição. A estética, o belo, a sensibilidade, são partes essenciais de uma realização que visa não só a dignidade, mas também a felicidade.

"É próprio do homem conjugar o mais alto e o mais baixo em sua natureza, e se sua dignidade repousa na severa distinção entre os dois, a felicidade encontra-se na hábil supressão dessa distinção. A cultura, portanto, que deve levar à concordância de dignidade e felicidade, terá de prover a máxima pureza dos dois princípios em sua mistura mais íntima." (SCHILLER apud SUZUKI In: SCHILLER, 2002)

Aquilo que apontamos anteriormente como um legado da obra kantiana, bem seja, esse arranjo sistemático do trabalha de Humboldt e, sobretudo no Cosmos, a apresentação de dois domínios metodológicos antagônicos são, em grande parte, fruto dessa concepção schilleriana do homem como medida de razão e sensibilidade. Assim como Schiller, Humboldt compreende que no homem há não só uma estrutura racional, mas que, em igual medida, fala nele a voz sensível da natureza que o liga aos elementos do mundo, aquilo que o faz um ser integrado ao processo de transformação. Essa noção de homem é que fundamenta, assim como em Schiller, a idéia de que a arte é a resposta para a confluência desses domínios contrapostos. A arte, assim como anuncia a proposta de gênio kantiana e a concepção 
VITTE, A.C. et al. Ciência e estética na ciência humboldtiana e os ...

estética de Schiller, está ligada ao processo de unificação e plena realização do homem. Do mesmo modo, a realização plena de sua atividade intelectual não pode ser dissociada da sua realização como ser. Ainda que essa noção tenha como influência fundamental as proposta de Goethe e Schelling, é o legado de Schiller, com quem Humboldt estabelece significativo diálogo por cartas, que estabelece a sua compreensão geral do humano.

Não pode realizar-se plenamente o homem ou a sociedade pelas vias únicas da razão ou dos sentidos, enquanto pensa abstratamente e de forma distante, esquece do sentimento que acompanha a necessidade mesmo de existir e não simplesmente pensar; por outro lado, enquanto simplesmente existe, sente e realiza, não manifesta o que o diferencia de tudo o mais, não passa de uma besta, um elemento da natureza como qualquer outro. A arte, nesse rumo, será a forma mais elevada de reunir o que em nosso desenvolvimento se separou. Como média entre razão e sensibilidade realizará a arte a comunhão final entre estes elos separados, permanece seu legado para além das mudanças e das opiniões, suas insígnias ressuscitam aos novos tempos o que de importante se construiu no projeto final de uma humanidade plena.

Chegamos agora ao conceito de ação recíproca entre dois impulsos, em que a eficácia de cada um ao mesmo tempo funda e limita a do outro; em que cada um encontra sua máxima manifestação justamente pelo fato de que o outro é ativo.

Esta relação de reciprocidade entre os dois impulsos é meramente uma tarefa da razão, que o homem só está em condições de solucionar plenamente na perfeição de sua existência. É a Ideia de sua humanidade, no sentido mais próprio da palavra, um infinito, portanto, do qual pode aproximar-se mais e mais no curso do tempo sem jamais alcançá-lo. "Ele não deve empenhar-se pela forma à custa de sua realidade, nem pela realidade à custa da forma; deve, antes, procurar o ser absoluto pelo determinado e o determinado pelo absoluto. Deve contrapor-se um mundo por ser pessoa, e ser pessoa por se lhe contrapor o mundo. Deve sentir por ser consciente e ser consciente por sentir." O homem não pode 
VITTE, A.C. et al. Ciência e estética na ciência humboldtiana e os ...

experimentar a sua concordância com esta Ideia, com sua humanidade no sentido mais pleno, enquanto satisfaz exclusivamente um destes impulsos ou os dois sucessivamente: pois, enquanto apenas sente, fica-lhe oculta a sua pessoa, ou sua existência absoluta, e, enquanto apenas pensa, fica-lhe oculta a sua existência no tempo, ou seu estado. (SCHILLER, 2002, p.73)

Atenta-se Schiller para uma questão importante, a do tempo. Na consideração dos impulsos sensível e racional deixa vir à tona o que nos parece fundamental na constituição da modernidade. Schiller (2002) dirá que o impulso sensível orienta a existência do ser, atesta um conteúdo que se vive temporalmente; a razão, por sua vez, busca a supressão desse tempo, a totalidade acabada, pura e simples. Enquanto existimos, a modificação se apresenta e é posta como parte de tudo quanto toma nossas realizações, contudo, este estado fugidio não pode e não representa o que de necessário se impõe ao homem. A solução schilleriana será a existência de um impulso lúdico, ponto médio entre vida e forma, que estará "direcionado, portanto, a suprimir o tempo no tempo, a ligar o devir ao ser absoluto, a modificação à identidade" (SCHILLER, 2002, p. 74).

A definição de impulso lúdico está justamente na relação de equilíbrio entre forma e existência, aquilo que busca a estética e o que concebemos mais elevadamente como beleza. "Se o espírito encontra, ao intuir o belo, um feliz meio-termo entre a lei e a necessidade, é justamente porque se divide entre os dois, furtandose à coerção de um e de outro." (SCHILLER, 2002, p.79). Aqui, como dissemos no início deste tópico, a estética toma para si leis tão precisas e uma determinação tão verdadeira quanto a razão prática na manifestação dos imperativos categóricos. Não é mais o espaço de uma variabilidade simplesmente, pelo que concatena na sua estrutura o formal e sua necessidade. O belo passa a ser elemento central na formação do homem pleno, já que esta atribuição estética, o gosto, está ligado à razão e à natureza. "Pela beleza, o homem sensível é conduzido à forma e o pensamento; pela beleza, o homem espiritual é reconduzido à matéria e entregue 
VITTE, A.C. et al. Ciência e estética na ciência humboldtiana e os ...

de volta ao mundo sensível" (SCHILLER, 2002, p.91). O equilíbrio ultrapassa em larga medida a via única: “(...) algo é certo: o poeta é o único homem verdadeiro, e o melhor filósofo é tão somente uma caricatura dele." (SCHILLER In: GOETHE e SCHILLER, 1993, p. 40).

A arte aparece, em suas variadas formas, como a procura do meio-termo. Aquelas que se prendem ao impulso sensível devem se direcionar ao formal, ao contrário, as ligadas à formalidade deve encontrar-se com o impulso sensível. Como não são plenamente suprimidos todos os limites e nunca cumprida a harmonia perfeita, resta a imagem da busca, a representação inacabada do Ideal estético. Também ao artista cabe esse modelar, esse refazer-se de si. Os ligados aos impulsos sensíveis devem se voltar ao formal, por outro lado, os envolvidos com o impulso formal, devem buscar a harmonia no impulso sensível. Esta é a medida da liberdade em Schiller e o valor da estética na educação. Segundo o próprio Schiller (2002): “(..) não existe maneira de fazer racional o homem sensível sem torná-lo antes estético.” (p. 113). Humboldt, comentando a opinião do duque d' Argyle, exprime que as ciências, em específico a teoria de Darwin, falha, ainda que reconheça uma dinâmica na natureza atrelada a uma concepção organicista, por não valorizar a arte, afinal, conhecer não é só apontar o funcional, o útil, mas reconhecer o papel do belo, da arte que evoca nossa realização como homens.

A teoria de Darwin, considera as espécies como exércitos sempre em guerra; não observa, portanto, senão as armas, quer dizer, os órgãos; esquece o belo, o ornato, e estético, é incompleta, na opinião do duqe d' Argyle. Segundo ele diz, far-se-ia apenas ideia insuficiente do poder criador, mostrando-o sem cessar submetido à acção e recusando reconhecer nas suas obras a expressão de um ideal de beleza, muitas vezes incompreensível pelo homem, outras vezes, porém, em visível harmonia com os nossos instintos estéticos. (1953, p. 326-327)

Este valor da arte, do elemento estético, a possibilidade de uma realização plena da humanidade pelas vias do gosto, pelo 
VITTE, A.C. et al. Ciência e estética na ciência humboldtiana e os ...

papel da forma, pela dinâmica própria dos princípios reflexivos, que serão fundamentais na obra dos românticos e, sobretudo em Goethe. Humboldt é influenciado por essa concepção e a sua compreensão de homem; o papel que representa o elemento estético para sua compreensão da natureza parecem claramente ligados ao que se apresenta na proposta schilleriana.

\section{Goethe: arte e método em Humboldt}

A primeira e mais importante influência em Johann Wolfgang Goethe (1749-1832), no que se refere a arte, advém de Winckelmann $^{1}$ (1717-1768), que, com seu retorno aos clássicos, recuperou o sentido posto pelos modelos universais gregos ao tempo nascente. Segundo o próprio Goethe, em Correspondência enviada à Schiller em 21 de agosto de 1799: "Estudei com afinco a vida e a obra de Winckelmann. Preciso esclarecer em pormenores o mérito e a atuação desse bravo homem" (GOETHE \& SCHILLER, 1993, p. 187). O modelo é, para Goethe, parte

${ }^{1}$ Por não ter participado do florescer do Renascimento pelo papel central desempenhado pela Reforma, experimentará a Alemanha, com a obra de Winckelmann (1717-1768), sua própria "Renascença", um marco da mudança que será levada a cabo na Alemanha com o Sturm und Drang e com o romantismo. O retorno aos clássicos encontra na cultura grega uma importância sem paralelo, uma representação perfeita a ser buscada na elaboração de uma técnica que permitisse a execução do projeto imortal de uma civilização plena (RICOTTA, 2003). Desta feita, a arte romana será considerada uma imitação inepta das obras gregas, servindo somente como residual demonstração de uma técnica mais elevada. O retorno aos gregos é a maneira pela qual se manifestará na Alemanha a possibilidade de uma nova forma de compreender e vivenciar a realidade. Único povo capaz, ou que se vê capaz, de responder ao desafio de construir historicamente uma organização tão plena como a daqueles antigos, os alemães tomarão para si o desafio da humanidade, pretenderão carregar em sua intelectualidade e história o projeto humano. Nas palavras do próprio Winckelmann (apud MACHADO, 2006): "O único meio de nos tornarmos grandes e, se possível, inimitáveis, é imitar os antigos.” (p.13). 
VITTE, A.C. et al. Ciência e estética na ciência humboldtiana e os ...

importante da própria composição da realidade, estabelecer, portanto, uma produção deste ideal da arte nos gregos é caminhar rumo a uma reprodução criadora; é realizar na arte a tarefa maior de aproximar o invariável e universal ao particular e contingente.

É pela descoberta da arte dos antigos como desenvolvimento de uma expressão regrada, regulada pela natureza, que Goethe há de elaborar e configurar a sua própria qualidade poética, "o modo grego de poetar", o modo ingênuo que se distingue do sentimental, distinção assumida mais tarde na oposição entre classicismo e romantismo. (MOLDER In: GOETHE, 1992, p. 10 - fich.)

A ligação entre Goethe e Schiller se apoia sobretudo nesse aspecto da visão artística: no vínculo que ela estabelece com a transformação da natureza; no papel dos clássicos e, mais ainda, no valor dado ao sensível em oposição à pura abstração. A visão da arte como Ideal é também o que diferencia Goethe do primeiro romantismo alemão. Em Goethe, o invariável, o arquétipo, que, no caso da arte é buscado na obra grega, revela o caráter ideal da obra de arte, a ligação do particular e do geral; nos primeiros românticos, como veremos, a arte se apoia na visão de um mediumde-reflexão, ou seja, as formas se desdobram no processo de sua formação, o que há não é um ideal, mas uma ideia da arte, que, nesse sentido, é afim à reflexão na forma. Além do que, em Goethe é valorizada a intuição como maneira de alcançar a dinâmica no instante, já nos primeiros românticos, o desdobramento reflexivo no conceito é que permite a união das formas no absoluto. (BENJAMIN, 2002).

Importante é que Goethe e Schiller estabeleceram no seu encontro fortuito a interlocução necessária à elevação do pensamento, marcando, por suas correspondências, um período relevante do pensamento alemão. Iniciada em 1794, estas correspondências se estenderam até a morte de Schiller no ano de 1805, como ressalta Cavalcanti (In: GOETHE \& SCHILLER, 1993): 'Se Goethe em 1817 chamou de 'feliz acontecimento' o seu 
VITTE, A.C. et al. Ciência e estética na ciência humboldtiana e os ...

encontro com Schiller, já em 1800 este diria que tê-lo conhecido havia sido o 'melhor acontecimento' de toda a sua vida." (p. 17). Nessas correspondências o tema da arte nunca é abandonado, mesmo porque nos projetos científicos de Goethe se apresentará sempre uma composição, uma integração entre arte, filosofia e ciência que reflete na forma de aproximação o próprio conteúdo das ideias. Embora se destaque com frequência o papel de Goethe na arte literária, e se reduza a importância de suas contribuições filosóficas e científicas, ele mesmo nunca as dissociou; entendia como necessidade e forma mais elevada de pensamento a integração destas diferentes esferas; fez de sua vida a concatenação destes campos, e de suas obras o máximo de sua representação. Não definiu apropriadamente uma doutrina filosófica, não segmentou ou compartimentou analiticamente seu pensamento, mas revelou em seus trabalhos, científicos e literários, uma forma peculiar de entendimento. E é, enfim, essa a temática das correspondências com Schiller (GOETHE \& SCHILLER, 1993), uma ligação que terá ainda como ponto importante o valor dado ao empírico, ao sensível, o que os distancia em alguma medida do idealismo que tomará a Alemanha romântica do início do século XIX.

Schiller, dirá que é importante reconhecer a sensibilidade no homem e, mais ainda, encontrar no equilíbrio entre a racionalidade e o sentimento a forma plena de realização da vida e da humanidade. Com Goethe, de uma forma diferente, o mesmo acontece. O empírico, o finito, demonstrará na sua figura uma relação com o infinito; se apresentará a transformação como expressão de um diálogo aberto entre o universal e o particular; visível e invisível se confluem e, nessa confluência, se apresenta a perspectiva da formação em Goethe e a maneira como ele estruturará seu método morfológico.

O papel da arte em Goethe, assim como em Schiller, assenta na função mediadora, na capacidade da obra de arte concatenar subjetividade e objetividade numa via mais do que explicativa, porque simbólica, e diretamente correlata à própria dinâmica de formação da realidade. $\mathrm{O}$ homem é maior na arte, nela penetra e se 
VITTE, A.C. et al. Ciência e estética na ciência humboldtiana e os ...

torna unidade com a natureza, supera a distância entre sensibilidade e razão, fluindo em harmonia os polos antagônicos que exprimem a realidade. A intuição compreende a realidade na sua pura forma; apreende a dinâmica no instante; a ligação permanente entre o todo e as partes. Não obstante, é a arte a representação objetiva deste processo, a interiorização e exteriorização no homem de um processo que forma a realidade. Com a arte, pode o gênio exprimir em si e no mundo a mesma orientação geral posta à natureza. Aquele que pode apreender na intuição e revelar na arte a dinâmica da forma, caminhando rumo ao verdadeiro saber, que, em realidade, é mais do que saber, é conhecer e ser o que se pretende conhecido. Segundo Goethe (1993b): “(...) a obra de arte deve provir do gênio: o artista deve extrair forma e conteúdo do fundo de sua própria essência, deve proceder como senhor da matéria e aproveitar as influências externas apenas para sua formação.” (p. 167). Esta é a função da arte em Goethe e, como veremos, é por ela, juntamente com as contribuições da ciência e da filosofia, que se tornará possível o método morfológico incorporado por Humboldt.

Em sua Metamorfose das Plantas (1992) podemos ver a maneira pela qual Goethe pretende a validação desse método; é, enfim, nessa obra, que se revela a representação estrutural dessa tentativa de uma nova ciência. A opção pelo reino vegetal é consagrada em função da possibilidade mais pronunciada de se reconhecer o conjunto dinâmico das transformações em suas diferentes etapas e condições. $\mathrm{O}$ anúncio das formas pela germinação e a sequência de alterações são mais bem reveladas na morfologia do mundo vegetal. É também esta forma mais facilmente ligada à representação artística, elemento central nesta reflexão sobre a realidade. Para Humboldt, a valorização do reino vegetal se dá no aspecto predominante que encerra na contemplação da paisagem, ela revela de maneira plena a impressão do geral no ato de incorporar a totalidade no instante. 
VITTE, A.C. et al. Ciência e estética na ciência humboldtiana e os ...

$\mathrm{Si}$ es certo que el verdadero carácter de cada region depende á la vez de todos los detalles esteriores; si los contornos de las montañas, la fisionomia de las plantas y de los animales el azul del cielo, la figura de las nubes, la trasparencia total, es preciso reconocer tambien que el adorno vegetal de que se cubre el suelo es la determinante principal de esta impression. (1874a., p. 331-332)

Doutra feita, essa vegetação é a origem da dinâmica, o elemento que carrega o princípio elementar da vida, é ela quem agrupa na forma, e aqui o elemento central da Morfologia, o processo formação-transformação que identificamos anteriormente com a regulação ideal do protótipo e do protofenômeno.

As plantas tendem incessantemente a dispor em combinações harmônicas a matéria bruta da terra; têm por ofício preparar e misturar, em virtude de sua força vital, as substâncias que, depois de inúmeras modificações, hão-deser elevadas ao estado de fibras nervosas.(1952, p. 279)

Humboldt ainda destaca o fato de a vegetação ser a base de sustentação da vida, aquilo que no plano de desenvolvimento da natureza, representa a fonte primeira de reprodução: "O mesmo olhar com que abraçamos o tapete vegetal que cobre a terra, revelanos a plenitude da vida animal, alimentada e conservada pelas plantas." (HUMBOLDT, 1952, p. 279). Mas o caráter fundamental do valor das plantas está na ideia de metamorfose e no modo como ela se desenvolve.

Goethe (1992) atenta para o fato de que as partes externas das plantas se associam e assumem, parcial ou totalmente, a feição das formas próximas. Partindo desse ponto, admite que as partes tem uma fonte comum, uma matriz pela qual orientam seu desenvolvimento; não obstante, essa matriz geral existente já na semente encontra um conjunto de condições e relações com o ambiente e mesmo com as estruturas que tomam forma com o crescimento da planta. Como órgãos independentes e, ao mesmo tempo, dependentes de uma 
VITTE, A.C. et al. Ciência e estética na ciência humboldtiana e os ...

estrutura geral, se modificam e iniciam o processo alternado de progresso e regresso que caracteriza o desenvolvimento.

Desde a semente até o mais perfeito desenvolvimento das folhas caulinares, observamos em primeiro lugar uma expansão; em seguida, vimos, através de uma contracção, surgir o cálice; as pétalas, através de uma expansão; as partes sexuais, através de uma contracção; e em breve nos apercebemos da maior expansão no fruto e da maior contracção na semente. Nestes passos, conclui a Natureza irresistivelmente a eterna obra de reprodução bissexuada dos vegetais. (GOETHE, 1992, p. 48)

Passa então a observar os frutos e procurar neles o mesmo princípio e as mesmas leis atribuídas à metamorfose das outras partes da planta. $\mathrm{O}$ fruto revelaria a fecundidade escondida nas folhas, e, mesmo na semente, a formação dele estaria contida em germe. O fruto constitui, para Goethe (1992), o ponto máximo de expansão no desenvolvimento da planta, o ápice pelo qual se reconhece a potência tornada externa. "Em contrapartida, descobrimos que a semente se encontra no mais alto grau de contração e elaboração do seu interior." (GOETHE, 1992, p. 49). Nesse processo de expansão e contração se realiza a formação da planta; em cada nó se cumpre o princípio e as leis metamórficas; das condições e limites à potência contida em germe se dá o desenvolvimento da planta. Segundo Humboldt: "Deixando certa liberdade ao desenvolvimento anômalo das partes, o organismo, em virtude de um poder primordial, submete todos os seres animados e todas as plantas a tipos definidos que se reproduzem eternamente." (HUMBOLDT, 1952, p. 283)

Considerada particular, essa planta é ainda um geral nos seus domínios; ao mesmo tempo, ligando-se a tudo o mais e, sua formação, não pode dissociar-se do conjunto da natureza, da relação com a totalidade e consigo mesma. Apreender essa relação é o desafio: como proceder diante de um objeto que, na verdade, esta em constante construção, em contínua relação com a totalidade? Como 
VITTE, A.C. et al. Ciência e estética na ciência humboldtiana e os ...

explicar um objeto se essa tentativa é já a tomada do objeto pelo sujeito, é já um relacionar-se e exerce-se como agente na relação com o que se pretende investigar? É então que se apresenta o método morfológico goetheano. Buscando no empírico o invariável, no exame recorrente do particular o universal, o método de Goethe será a expressão de uma nova forma de agir cientificamente. Na verdade, ciência, arte e filosofia se integrariam na busca por intuir na forma a dinâmica de uma relação todo-partes, subjetivo-objetivo, expansão e contração. Apreender as transformações não é possível por um procedimento que ignore as forças aí atuantes; bem entender a realidade é, antes de tudo, proceder de maneira ampla e condizente com os ditames de uma realidade sempre móvel. A representação não pode nunca alçar à realidade como ela se manifesta, mesmo porque este estado efêmero se esvai na tentativa de um caminho explicativo; não pode ainda corresponder a representação ao que de fato existe, pelo aspecto restritivo de se tomar pelo sujeito o que é resultado de uma confluência entre este e o objeto. $\mathrm{O}$ olhar do artista-filósofo-cientista é, portanto, um ponto necessário na execução desse fim, desse empreendimento que se mostra numa difícil e prolongada missão. "Encontramos, por conseguinte, no curso da arte, do saber e da ciência, várias tentativas para fundar e desenvolver uma doutrina, a que gostaríamos de chamar Morfologia." (GOETHE apud MOLDER In: GOETHE, 1992, p. 68) Para Humboldt, a arte pode e deve fazer parte das análises científicas, seus esforços são justamente no sentido de reagrupar estes domínios e fundar uma ciência capaz de compreender a dimensão artística na construção do conhecimento.

Papel fundamental nesse processo tem a intuição, ela é a captação da dinâmica no instante; é a forma de se apropriar de uma relação ampla por um penetrar do sujeito no objeto, por uma ligação do ser com a totalidade; é, enfim, a maneira do homem apresentar-se como parte dessa dinâmica. A valorização da arte está justamente na concepção que se atrela a ela de uma correspondência com a unidade geral da realidade; proposta que, já anunciada pela estética kantiana, é em Goethe e no idealismo 
VITTE, A.C. et al. Ciência e estética na ciência humboldtiana e os ...

romântico alemão do século XIX levada ao extremo. Nesse sentido, não pode um homem da ciência, pelas vias formais da razão, compreender o que quer que seja, na medida em que força a realidade a falar o que ele quer ouvir, impondo seu procedimento e fazendo calar a voz da natureza. Humboldt (1952) aponta essa questão nos Quadros da Natureza:

As plantas doentes, encerradas em nossas estufas, não representam senão muito incompletamente a majestade da vegetação tropica; mas, na perfeição da linguagem, na brilhante fantasia da poesia, e na arte imitadora da pintura, há manancial abundante de compensações onde nossa imaginação pode encontrar as imagens vivas da natureza exótica (p. 299)

Entender a realidade é nela penetrar, buscar in situ as condições de manifestação da realidade; incorporar-se ao conjunto de coisas e dele retirando o que lhe cabe no momento da reflexão; proceder pela via de uma comunicação sempre aberta e integrada entre o sujeito e o objeto; reconhecer o que há de si mesmo na forma e o que da forma acaba por lhe tocar, é, enfim, mais do que fazer ciência, é estar-se ligado com um mundo que modifica e é modificado constantemente por cada elemento que nele existe. Passivo e ativo, o sujeito que observa também atua, intui a totalidade no instante; age na transformação desse conjunto; tornase também ele um particular no geral e, por sua arte, reproduz para além da explicação essa ampla relação inexprimível.

As observações da natureza satisfazem-me muito. Parece estranho, mas é natural, que por último deva aparecer uma espécie de conjunto subjetivo. Na verdade, torna-se, como quer o senhor, 'o mundo do olho', que é esgotado através de forma e cor. Pois se atentar bem, então precisarei só muito pouco dos recursos dos outros sentidos, e toda a racionalidade transforma-se numa espécie de representação. (GOETHE \& SCHILLER, 1993, p. 92-93)

Também na sua Doutrina das Cores (1993b) Goethe exprimirá essa ideia de uma relação sempre aberta entre o sujeito e 
VITTE, A.C. et al. Ciência e estética na ciência humboldtiana e os ...

o objeto, demonstrando o papel crucial do observador e agente. A postura de Goethe (1993b) nessa obra é a de quem procura enfrentar o racionalismo científico no seu maior domínio: a física.

Parte ele, nesse enfrentamento da ciência da natureza racionalista, de um ponto fundamental do seu método e do filosofar que o subjaz, a ideia de que há uma relação inelutável entre o sujeito e o objeto. A proposta newtoniana (NEWTON, 1979b) para a compreensão do fenômeno cromático é de origem mecânica, aplica as constatações inferidas por estudos experimentais sobre o comportamento fenomênico da luz e suas propriedades refratárias e reflexivas na formação das cores. Goethe (1993b), primeiramente, considerará três formas de manifestação dos fenômenos cromáticos: a primeira fisiológica, ligada à condição do olho é na receptividade e atividade que resulta na formação das cores; a segunda física, correlata às ideias apresentadas pelo procedimento newtoniano, ou seja, tomada pelas propriedades reflexivas e refratárias na apresentação das cores, e a terceira, chamada química, atribuída à propriedade dos corpos em sua composição.

O sujeito é considerado na formação das cores; o que fora considerado por Newton somente na perspectiva negativa, ou seja, como uma deturpação do que se apresentava de fato na experiência, aparece em Goethe como elemento central da explicação do fenômeno É evidente que se trata aqui de uma diferença metodológica e filosófica, já que a forma como se entende os fenômenos é totalmente diferente, sendo a postura newtoniana estritamente mecânica e filosoficamente dogmática, ao passo que a de Goethe, é diretamente ligada a noção de uma causalidade não-linear envolvendo todo e partes e articulada ao papel fundamental do sujeito na consagração do objeto. Mais do que simplesmente apreender o mundo de uma forma particular ou do alto de uma categoria, a proposta goetheana visa apresentar o sujeito como ativo: o olho tem luz própria; por sua condição recebe e age sobre o campo dos fenômenos; é parte e cria, na sua relação com a totalidade, a cena que pretende analisar e exprimir. 
VITTE, A.C. et al. Ciência e estética na ciência humboldtiana e os ...

Goethe estava convencido de que a totalidade da natureza se revela, como que através de um espelho, ao sentido da visão. Se tanto luz quanto cor pertencem à natureza que por sua vez se mostra particularmente na visão, é esta última, portanto, que contém a solução do enigma. De modo análogo à revolução copernicana de Kant, Goethe transfere o olhar divino de Plotino, até então simbolizado pela luz, para o interior da nossa visão. $\mathrm{O}$ olho se torna luminoso... (GIANOTTI In: GOETHE, 1993b)

No caso da perspectiva física não há uma reprodução da concepção newtoniana, muito pelo contrário; os fenômenos são entendidos a partir de um fenômeno primordial (GOETHE, 1993b, p. 90). Esse fenômeno é o ideal na relação com o empírico, no caso das cores, o equilíbrio dinâmico entre claro e escuro; luz e sombra, donde se media a formação gradativa cromática.

Na perspectiva química se atribuí cor aos corpos, que podem ser modificadas, intensificadas ou transmitidas pelas relações existentes entre estes; são marcadas por sua durabilidade em relação aos outros dois anteriores. A composição é dada pela junção das cores básicas, que, nas diferentes gradações formam uma mistura real ou aparente, compreendendo, assim, a totalidade das cores dos corpos. Nesse sentido é que Goethe (1993b) vai atacar a noção de que o branco é formado a partir da conjunção das cores, uma vez que estas são sempre mais escuras do que o branco e se distanciam progressivamente desse polo na linha gradativa entre claro e escuro. A importância do reino vegetal é novamente destacada por Goethe (1993b) nesse trabalho, admite ele que são as plantas e seu processo de formação que melhor compreendem essa transformação química das cores, chamando mesmo a alteração das cores no reino vegetal de “operação química superior” (GOETHE, 1993b, p. 114).

A formação das cores representaria a ligação harmônica na escala gradativa de claro e escuro, de modo que essa unidade é em si uma totalidade. Além de reagrupar harmonicamente os polos gradativos, a cor representa a junção do sujeito que apreende-atua sobre o que se torna objeto da sua observação. "Apresentando-se 
VITTE, A.C. et al. Ciência e estética na ciência humboldtiana e os ...

ao olho em sua grande variedade, a cor se torna, na superfície dos seres vivos, uma parte importante dos signos exteriores, através dos quais percebemos o que se passa no interior deles." (GOETHE, 1993b, p. 132).

É a ligação que Humboldt introduz na construção de uma ciência inovadora. O sujeito está em plena relação com o objeto; não se trata aqui de simplesmente observar à distância e com imparcialidade, ao contrário, é o anuncio de uma via aberta, o reconhecimento que já se coloca em Goethe de uma dupla troca entre o observador e o que se dispõe à observação.

Muitas vezes, a impressão que nos causa a vista da natureza, deve-se menos ao próprio caráter da região do que ao dia em que nos aparecem as montanhas e as planuras aclaradas pelo azul transparente dos céus, ou velados pelas nuvens que flutuam perto da terra. Do mesmo modo as descrições da natureza impressionam-nos tanto mais vivamente, quanto mais em harmonia com a nossa sensibilidade; porque o mundo físico reflete no íntimo do nosso ser em toda a sua verdade. (HUMBOLDT, Alexander, 1950, v. I p.211-212)

Aquilo que já se colocava pelo papel da filosofia da natureza de Schelling, ou seja, a relação existente entre o espírito e a natureza, é trazido para o plano da ciência. O que aponta Goethe em sua Doutrina das Cores, em detrimento de uma análise restrita da física newtoniana é o papel dessa Naturphilosophie numa nova forma de fazer ciência. Já não se pode impunemente falar de um mundo sem reconhecer a medida do humano nele. É por isso que, como fizemos questão de frisar anteriormente, não se pode falar numa exclusão do humano na análise que Humboldt faz acerca da natureza, afinal, trata-se de uma relação indissociável. O homem, na sua relação com o mundo, deixa-se influenciar ao tempo que também exerce influência.

Tudo quanto dá caráter individual à paisagem: o contorno das montanhas que limitam o horizonte num longínquo 
VITTE, A.C. et al. Ciência e estética na ciência humboldtiana e os ...

indeciso, a escuridão dos bosques de pinheiros, a corrente que se escapa de entre as selvas e bate com estrépito nas rochas suspensas, cada uma destas coisas tem existido, em todos os tempos, em misteriosas relações com a vida íntima do homem. (Idem. p. 212)

O objeto externo é dado em comunhão com a subjetividade, com aquilo que se apresenta no íntimo de cada um que se coloca a contemplação e compreensão da natureza. Mais do que um dado, a natureza é para o homem um elemento de construção, uma articulação que pressupõe não um fato, um acabado objeto, mas o remetimento ininterrupto à sua produção, àquele processo de formação-transformação que liga definitivamente homem e natureza.

Todo cuanto nuestros sentidos percíben vagamente, todo cuanto los parajes románticos presentan de mas horrible, puede llegar á ser para el hombre manantial de goces; su imaginacion encuentra en todo medios de ejercer libremente un poder creador. En la vaguedad de las sensaciones, cambian las impresiones com los movimentos del alma, y, por una ilusion tan dulce como fácil creemos recibir del mundo exterior lo que nosotros mismos sim saberlo hemos depositado en él. (1874a., p. 05-06)

Essa nova ciência humboldtiana está acentada na ideia inovadora de ciência em Goethe. Ciência, filosofia e arte devem confluir, devem mostrar na análise da forma que a natureza está em dinâmica, que ela se orienta por uma finalidade; devem suscitar pelo método a visão de um homem que não é só razão, mas também sensibilidade; devem, igualmente, aclarar que na arte, na representação da bela forma, se dispõe a relação inviolável entre o sujeito e o objeto que se lhe apresenta. O Homem e sua ciência, são o passo novo no sentido de uma humanidade plena, a representação máxima de uma natureza tomando, no sentido schellinguiano, "consciência de si".

Entender este processo é compreender o papel da arte no sentido pleno da humanidade, e, nesse caminho, compreender a 
VITTE, A.C. et al. Ciência e estética na ciência humboldtiana e os ...

concepção de arte no romantismo alemão, bem como o valor que ela assume na sistemática filosófica de Schelling são passos analíticos fundamentais.

\section{Considerações}

A ciência humboldtiana é o produto de uma riqueza e de uma forte complexidade do século XVIII, riqueza dada pelas diferentes formas de se interpretar e construir o mundo, a complexidade pela infindável quantidade de influências, artísticas, filosóficas e científicas a qual Alexander von Humboldt estava sujeito e participou ativamente da construção.

A ciência humboldtiana é o produto de uma relação entre o romantismo de Jena e o classicismo científico de Weimar, além de um redimensionamento da ciência newtoniana. As reflexões de Humboldt expressaram essa relação e o produto foi o nascimento da geografia moderna, produto de uma reflexão metafísica sobre a natureza e a estética de Schiller, onde a experiência estética foi o carro-chefe para a construção das principais leis geográficas, como as da conexão, da extensão e da relação entre a verticalidade e a horizontalidade na definição de um fenômeno geográfico, que apesar de sua diferenciação espacial e ambiental, articula-se com o transcendental, na medida em que concebe uma estética objetiva que se define por uma diferenciação dos fenômenos articulados em torno da razão e da sensibilidade.

\section{Referências bibliográficas}

BENJAMIN, W. O conceito de crítica da arte no romantismo alemão. Trad. e notas Marcio Seligmann Silva. São Paulo: Iluminuras, 2002.

GOETHE, J. W. von.. Doutrina das cores. São Paulo: Nova Alexandria, 1993. 
VITTE, A.C. et al. Ciência e estética na ciência humboldtiana e os ...

. A metamorfose das plantas. Trad., Introdução e Notas Maria Molder, Lisboa, Imprensa Nacional da Casa da Moeda, 1997.

. Viagem à Itália. Trad. Sérgio Tellaroli. São Paulo: Companhia das Letras, 1999.

PM Editores, 2001.

Os sofrimentos do joven Werther. Porto Alegre: L \& . Fausto. São Paulo: Martin Claret, 2002.

Máximas e reflexões. Trad. e notas José M. Justo. Lisboa: Relógio d'água, s.d.

. Teoría de la naturaleza. Trad. e notas Diego Sánches Meca. Tecnos, s.d.

GOETHE \& SCHILLER. Companheiros de viagem: correspondências. São Paulo: Nova Alexandria, 1993.

HUMBOLDT, Alexander. Cosmos: ensayo de una descripcion física del mundo. Trad. Bernardo Giner \& Jose de Fuentes. Madrid: Gaspar e Roig Editores, 1874a, Tomo I.

Cosmos: ensayo de una descripcion física del mundo. Trad. Bernardo Giner \& Jose de Fuentes. Madrid: Gaspar e Roig Editores, 1874b, Tomo II.

. Quadros da natureza. São Paulo: W. M. Jackson Inc., Vol. 1., 1952. (Clássicos Jackson)

. Quadros da Natureza. São Paulo: W. M. Jackson Inc., Vol. 2., 1953. (Clássicos Jackson)

- Cartas Americanas. Trad. Marta Traba. Venezuela: Biblioteca Aycaucho, s.d. 
VITTE, A.C. et al. Ciência e estética na ciência humboldtiana e os ...

KANT, Immanuel. Crítica da faculdade de julgar. Rio de Janeiro: Forense Universitária, 1995.

Crítica da razão pura. São Paulo; Nova Cultural, 1999 (Os Pensadores)

MACHADO, R. O nascimento do trágico: de Schiller a Nietzsche. Rio de janeiro: Zahar Editor, 2006.

NEWTON, Isaac. Princípios matemáticos. São Paulo: Abril Cultural, 1979, p. 1-22. (Os pensadores)

Óptica: livro III, parte I, referente às questões. São Paulo: Abril Cultural, 1979b, p. 23-57. (Os pensadores)

RICOTTA, Lúcia. Natureza, Ciência e estética em Alexander von Humboldt. MAUD, 2003.

SCHELLING, F. Obras escolhidas. Sel., Trad. e notas Rubens Rodrigues Torres Filho. São Paulo: Abril Cultural, 1979. (Os Pensadores)

- Ideias para uma filosofia da natureza: prefácio, introdução e aditamento à introdução. Lisboa: Imprensa Nacional Casa da Moeda, 2001a.

Filosofia da Arte. Introd. E notas Márcio Suzuki. São Paulo: Editora da Universidade de São Paulo, 2001b, p. 09-143.

SCHELEGEL, F. O dialeto dos fragmentos. Trad., apresentação e notas Márcio Suzuki. São Paulo: Iluminuras, 1997.

SCHILLER, F. A educação estética do homem: numa série de cartas. Trad. Roberto Schwarz e Márcio Suzuki; Introdução e notas Márcio Suzuki. São Paulo: Iluminuras, 2002. 